\title{
PRESSURE-BASED PIPE CONDITION ASSESSMENT FOR INTELLIGENT WATER NETWORK MAINTENANCE
}

\author{
L.L. Lopez*, J.E. van Zyl \\ Department of Civil and Environmental Engineering, University of Auckland, New Zealand \\ ${ }^{*}$ Corresponding author
}

\begin{abstract}
Adopting a proactive approach in water distribution asset management can translate into substantial benefits on the overall cost efficiency and levels of service of the network. Such approaches are generally based on individual failure risk analysis and result in pipe rehabilitation/replacement prioritisation schemes. Due to the cost of the available pipe assessment technologies, most risk analysis models do not use direct indicators of the network's structural health but rely on indirect variables such as age, pipe material and burst history to predict failure probability.
\end{abstract}

This work presents a novel non-intrusive condition assessment device for pipe and valve leakage characterization, providing risk analysis models with a direct indicator of the current state of the network. The condition assessment device is a self-contained and mobile system consisting of a water tank, pump, flow meters, pressure sensors and other instrumentation. The device characterises leaks by evaluating the behaviour of leakage flow with changes in the pipe pressure.

The data obtained from the device is used in a performance-based prioritisation model with other available data to better manage water distribution network maintenance. In addition, a periodic condition assessment of the network can be used as a standard monitoring method that will support a dynamic pipe deterioration model, thereby improving the model's prediction accuracy.

\begin{tabular}{ll}
\multicolumn{2}{l}{ Notation } \\
$A$ & Area of the leak \\
$A_{0}$ & Initial Area (area at zero pressure) \\
$C_{d}$ & Discharge coefficient \\
$C$ & Leakage coefficient \\
$\mathrm{g}$ & Acceleration due to gravity \\
$h$ & Head differential across leak opening \\
$m$ & Head-area slope \\
$N 1$ & Leakage exponent \\
$\mathrm{Q}$ & Leakage flow rate
\end{tabular}

\section{Introduction}

Good asset management and operation of water distribution systems are key to ensuring a safe, cost-effective and sustainable service to the public. In recent decades the deterioration (often quantified through leakage) of distribution systems has attracted a great deal of attention from consumers, practitioners and researchers (Jafar et al., 2010; Kimutai et al., 2015; Romano et al., 2010). This is due to a significant proportion of pipe assets reaching their replacement age, growing water demand and increasing stresses on natural resources (Sanz et al., 2016). Water losses is a substantial problem on an international level with significant economic, environmental, sustainability and health implications (Fox et al., 2017).

Significant progress has been made in understanding the deterioration of water distribution pipes using a wide range of approaches (Ward et al., 2017; Zeng et al., 2018). These approaches can be broadly classified as Leakage localisation or pinpointing methods and pipe break predictors. Leakage localisation or pinpointing methods rely on technologies such as acoustic logging, ground penetrating radars, noise correlators and transient waves. Other more accurate (but expensive) techniques in this classification are automatic meter reading, tracer gas injection and pig-mounted acoustics (Puust et al., 2010). Pipe break predictors are statistical or physically based models that use characteristic data from the pipes and their surroundings, historical breakage data (only statistical), and corrosion pit measurements (some physical) to obtain the pipe's remaining service life (Kleiner and Rajani, 2001; Rajani and Kleiner, 2001). However, the highlighted localisation and pinpointing methods are vulnerable to constraints such as pipe material, pipe depth or the size and location of the leak. As for the pipe break predictors, usually they do not include any direct indicator of the current state of the pipe, or they require data that is rarely available and it is hard to obtain. In sum, few of the existing technologies are able to characterise the condition of pipe assets in a non-intrusive 
and cost-effective way. As a result, most prioritisation techniques for pipe replacement or rehabilitation lack direct indicators of the structural health of the pipes and of the water losses generated by the current state of the assets.

The objective of this study was to develop an integrated pipe condition assessment system based on the latest understanding of the behaviour of pipe leaks with pressure (Cassa et al., 2010; Cassa and van Zyl, 2013; Greyvenstein and Van Zyl, 2007; Schwaller et al., 2015; Schwaller and van Zyl, 2015; Ssozi et al., 2016; van Zyl and Cassa, 2014; van Zyl and Clayton, 2007). The system allows municipalities to assess the condition of pipes and valves in distribution system pipes and generate condition data that can be used in combination with data from other sources to optimize system maintenance, create performance-based prioritisation for the replacement of pipes and understand the factors that affect system deterioration.

The following section describes the theoretical background of the pipe condition assessment method. This is followed by a description of the pipe condition assessment system and its components. Next, the pipe condition assessment method is described and, finally, the implications and potential uses of the system are discussed.

\section{Background}

In the context of water distribution systems, leaks are unintentional discharges from an opening on a pipe, joint, valve or other element. Orifice hydraulics is well understood for different shapes and conditions (Cassa and Van Zyl, 2011) and the flow of a jet through a leak opening can thus be estimated using the orifice equation:

$Q=C d A \sqrt{2 g h}$

Where $Q$ is the leakage rate, $A$ the area of the leak, $h$ is the head differential over the leak opening and $C_{d}$ the discharge coefficient. This coefficient accounts for energy losses and the difference between the areas of the jet and the leak opening.

Leakage practitioners found that Equation (1) does not provide a satisfactory model for individual leaks (ASCE, 1897) or the total leakage of a system. In fact, in practice the square root relationship between flow rate and pressure head seemed only valid for a small set of cases. Consequently, leakage practitioners adopted a power equation to describe leakage behaviour (Lambert, 2000). This equation is known as the N1 power equation and is given by:

$Q=C h^{N 1}$

where $C$ is the leakage coefficient and $N 1$ the leakage exponent. It should be noted that making the exponent a variable severs Equation (1) from its fluid mechanics' foundations, thus Equation (2) becomes simply an empirical equation. Field work has shown that the leakage exponent can vary significantly, with values between 0.4 and 2.9 being reported (Schwaller and van Zyl, 2015).
Reasons for the departure of the leakage exponent from 0.5 have been studied by many authors (i.e. Ferrante et al.,2011; Gebhardt, 1975; Van Zyl and Clayton, 2007; Walski and Weir, 2006). These factors include pipes material behaviour (causing leak areas to vary with pressure), soil hydraulics, leak hydraulics, water demand and the distribution of leaks in a network. However, pipe material behaviour has been shown to be the main factor responsible for the observed behaviour (Cassa and van Zyl, 2011; van Zyl and Cassa, 2014; van Zyl and Malde, 2017; van Zyl et al., 2017).

The variation of the leak area with pressure has been demonstrated to follow a linear relationship for elastic and viscoelastic material behaviour (Cassa et al., 2010; Ssozi et al., 2016). This linearity holds true irrespective of the leak opening type and size, pipe material, section properties and loading state.

The combination of Equation (1) with a linear pressure-area relationship results in the modified orifice equation (Cassa et al., 2010; Ledochowski, 1956; May, 1994):

$Q=C d \sqrt{2 g}\left(A_{o} h^{0.5}+m h^{1.5}\right)$

Where $A o$ is the initial leak area (area under zero pressure conditions) and $m$ the head-area slope. Equation (3) is the basis of the so-called "Fixed and Variable Area Discharges" (FAVAD) concept.

The modified orifice equation can be applied to a single leak, a system or a pipe with multiple leaks. Since the leak area is a linear function of pressure, a system's initial area is approximately equal to the sum of individual leak initial areas. Similarly, the system's head-area slope is approximately equal to the sum of the individual head-area slopes of all the leaks in the system (Schwaller and Van Zyl, 2015).

A main advantage of the modified orifice equation is its ability to estimate the physical leakage characteristics of pipe leakage through a pressure test. This test consists of a series of pressure steps with associated measurement of leakage flow rates, which allows the initial leak area and head-area slope to be determined. These values can then be used to estimate the dominant type of leak (round hole, longitudinal crack or circumferential crack) in the pipe.

Evidence shows that there are characteristics values of $m$ for each type of pipe crack for different pipe materials and classes (Greyvenstein and van Zyl, 2007). For instance, in longitudinal cracks and corrosion clusters, the $m$ values are normally positive, and much higher than for round holes. On the other hand, in circumferential cracks, the $m$ values are often negative, due to this type of leak's unusual tendency to close with increasing pressure.

Finally, it is possible to obtain the pipe's condition deterioration rate by analysing the characteristics of its leaks at different points in time. These deterioration patterns can also be correlated with other types of data such as pipe material, type of joint, soil properties, type of crack found, etc. Such 
data, in turn, can be useful in developing better maintenance and rehabilitation master plans.

\section{Pipe Condition Assessment System (PCAS)}

The primary function of the PCAS is to identify leaking valves, illegal connections and individual leaks present in the pipeline, characterizing the leakage by size and type. However, the data generated also provides the basis for better prioritisation of leak repairs and maintenance interventions.

The PCAS consist of one or more Pipe Condition Assessment Devices (PCADs), an Android mobile application and a cloudbased management system.

The Pipe Condition Assessment Device (PCAD), shown in Figure 1 , is a self-contained mobile device consisting of a water tank (A), generator (B), electronic control system (C) and a pump system (D). The hydraulic unit includes a pump, flow meters, valves and a pressure sensor. The electronics unit is composed of a control panel, GPS unit, GSM connection and a central processing and communication unit. All the units are installed on a hand-drawn trolley allowing it to be easily moved by a single operator (See Figure 2). Finally, the dimensions of the device itself make it easy to store and transport, as it is designed to fit through a standard building door.

Figure 1. Pipe Condition Assessment Device (PCAD) components

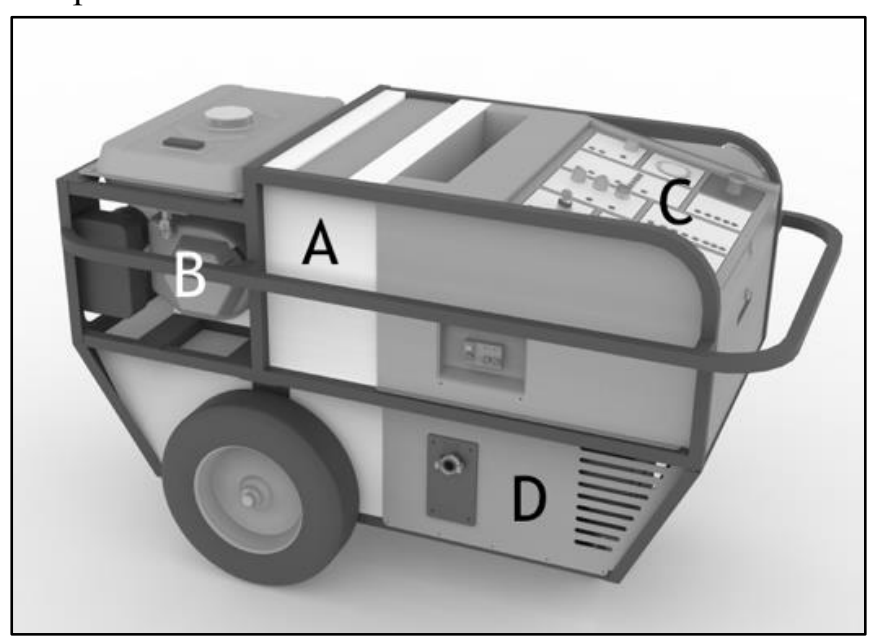

In the field, operators connect the PCAD to a pipe in the water distribution system using a fire hydrant, scour valve or dedicated connection point. Once the device is connected, the operators are able to navigate through the four possible processes: tank filling, isolation and valve breach, leak test and tank dumping. The values of flow and pressure are continuously recorded through all the processes along with other associated metadata. The metadata saved for the whole test is GPS location, detected errors, etc. As for each process, the common values are time, duration and result.
The Android mobile application is meant to guide and assist the operators through every step in the scheduled tests. Each PCAD unit has GIS and GPS functionalities, that guides the operators from pipe section to pipe section to be tested. After the operators start a test, it will aid in identifying the hydrant to connect to, valves to close and house connections to isolate (Figure 3). In case of an error or inconclusive result in any of the processes, the application can be used to get a more comprehensive explanation of the problem and possible actions to mend it. In addition, the application works as a feedback tool for the operators. Where they can attach (to the current test) pictures and comments of problems observed in the field.

Figure 2. A PCAD being moved with a full tank

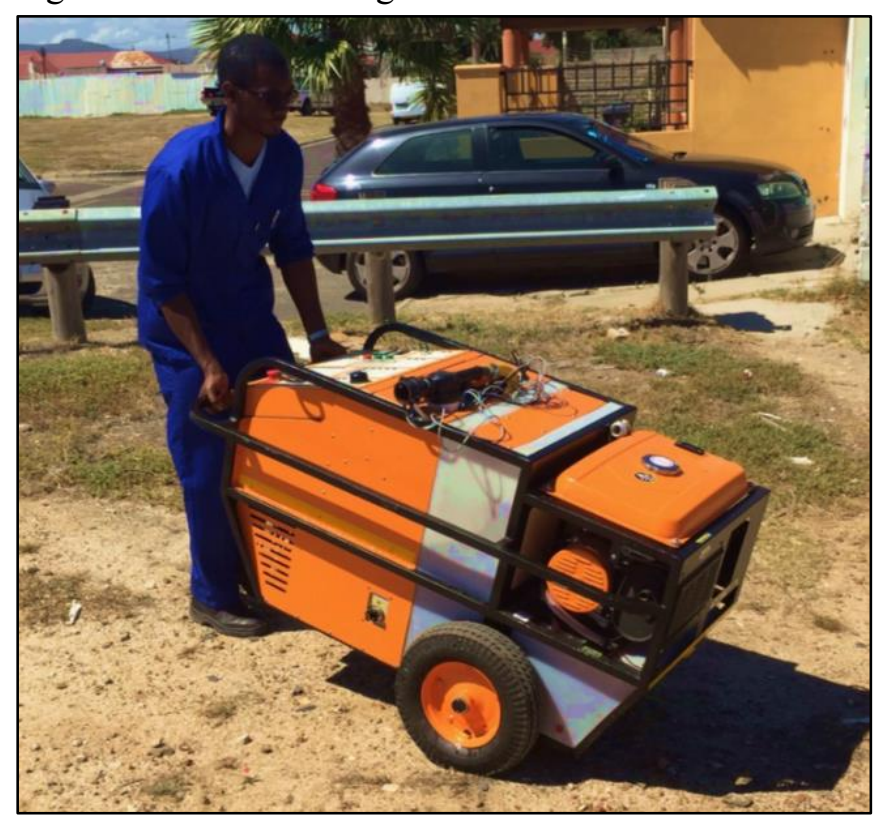

The cloud-based management system consists of a database management unit, a module of analyses and reports as well as a schedule builder. The database management unit helps to import, organize and relate other databases to the PCAS. At the least, the PCAS database would have the georeferenced location of pipes, valves and hydrants with their associated test results. Nevertheless, any other numerous types of information and/or data sources can be added/linked to the PCAS. Some examples are soil types, underground water sources, layouts of other buried networks, typical traffic loads, historic leak records, or simple detailed information of the water network's elements as age, material and type of joint.

The administration system's module of analyses and reports can be used to review the results of a specific condition assessment test (See Figure 4), create correlations between the different data types, or obtaining deterioration projections and prioritization schemes. And the schedule builder is a platform for utility managers to plan different condition assessment tests or pipe repair/replacement actions. In the case of a condition assessment test, the managers can also associate the teams and/or PCADs to the corresponding pipe sections. 
Figure 3. View of the water utility elements from the mobile App map.

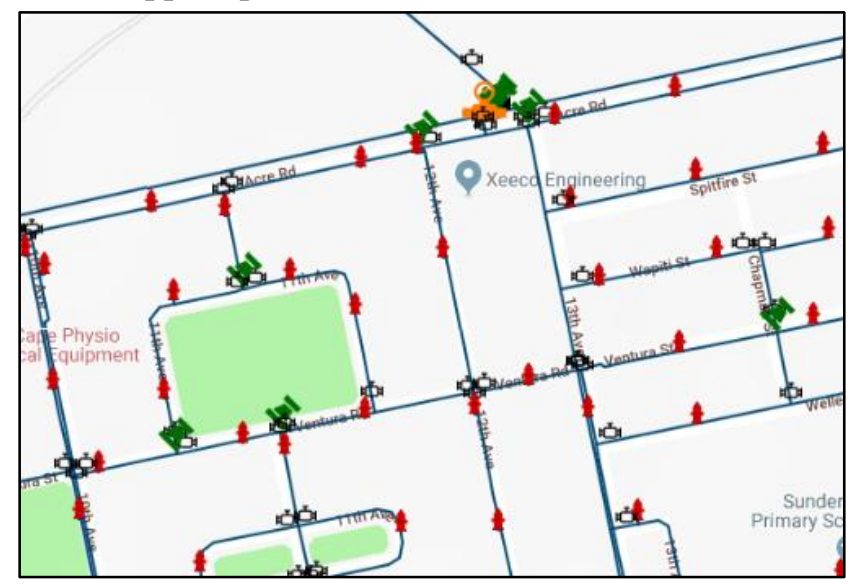

Finally, by using together all the components in the PCAS, water utilities can improve their operation, maintenance and rehabilitation strategies (see Figure 5). Yet every component is self-functional and has its own internal operational model. As they all have an independent connection to the system database with different access rights.

Figure 4. View of the results of a leak test on the management system's module of analyses and reports.

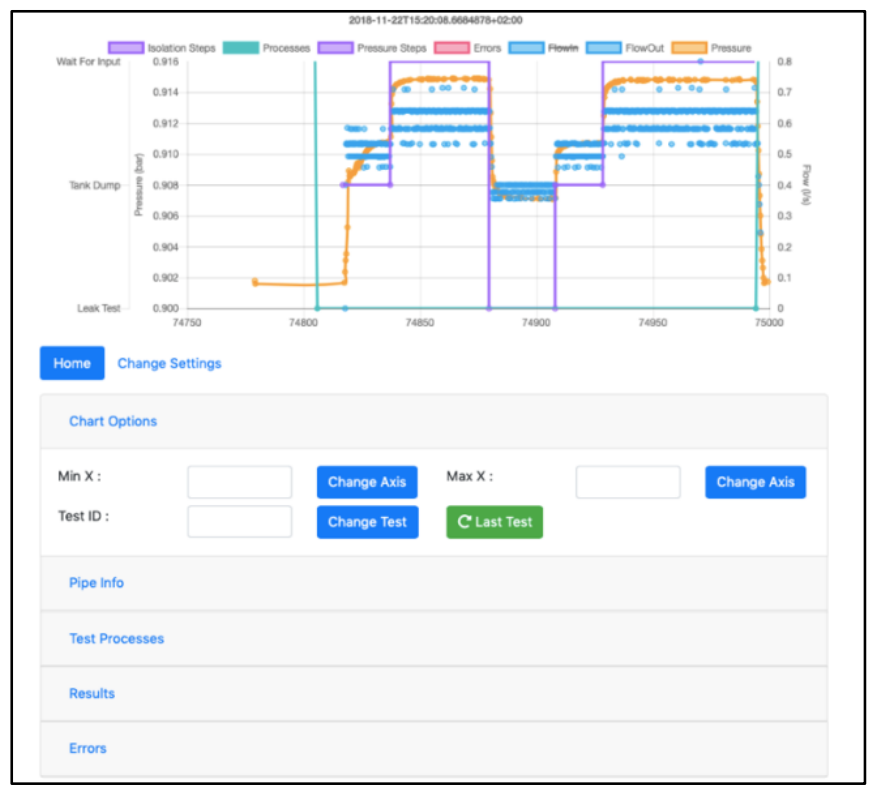

\section{Methodology}

The methodology is shown graphically in Figure 5.

The first step in the condition assessment of a pipe network is to use the cloud-based management system to plan and schedule pipe tests. To plan the tests, the managers can divide the network into suitable pipe sections (i.e. pipes that can be completely isolated from the network and have an entry point). The pipe sections will then be assigned to different teams and days according to the number of PCADs available.
The operators will use the mobile app to navigate through their schedules and get the necessary information to perform the test. In the case of any problem or anomaly in the system, they can report it using the application's various functions, such as taking photographs and adding reports automatically linked to GPS coordinates and uploaded to the management system.

In the location of a test, the operators first have to isolate the pipe section from any attached user connection. Then in the case the connection point is a hydrant, this should be flushed before to remove any sediments raised by its opening. After the pipe has been flushed, the PCAD is be connected to the pipe section and turned on.

The PCAD is designed as a finite state machine with six possible states: "Idle", "Waiting for an input", "Filling", "Isolation", "Leak test" and "Dumping". When the device is turned on it will start in the "Idle" state where all the components are initialized. Once the initialization is over and the device is ready, it will change state to "Waiting for an input". The operators are aware of a change of state by looking at the lights on the control panel. From the "Waiting for an input" state the control panel can be used to start and then stop any process. Processes will automatically stop after completion or detection of a fatal error. The operators can start any of the four processes an unlimited number of times and can change the default order should this be required.

When the device enters the "Filling" state, it will start filling the onboard tank using the network pressure head until the tank is full.

The isolation test is divided into three parts to ensure obtaining the best possible data collection. As the first part starts, the operators start closing the network valves. In the second part, the flush pipe is automatically opened to the atmosphere and the device will wait for a stable flow. A non-zero stable flow indicates that one of the isolation valves is not sealing. The third part is run if the pipe could not be isolated. In this part the device will close the flush pipe and then open it in steps to estimate the response of the valve breach flow to changes in pressure.

After the isolation test, the results will be: the system pressure, whether there is a valve breach or not, the size of the breach (if applicable) and the pressure step curve (in case there is a leak bigger than any existent breach). The process was developed to exploit the following two concepts:

- If there is a leak and the pipe is isolated, the device will sense a pressure drop before opening the flush pipe.

- If there is a breach, a continuous flow will be observed through the flush pipe once it is open. And it will mean that at least one of the valves did not isolate.

Although the test can be susceptible to false negatives and false positives (e.g. when the leak is as big as the breach), the measurements of a consecutive leak test would help to confirm the results in critical cases. 
Figure 5. Sequence diagram of an example set of operations, showing the interaction between the system's components and its users.

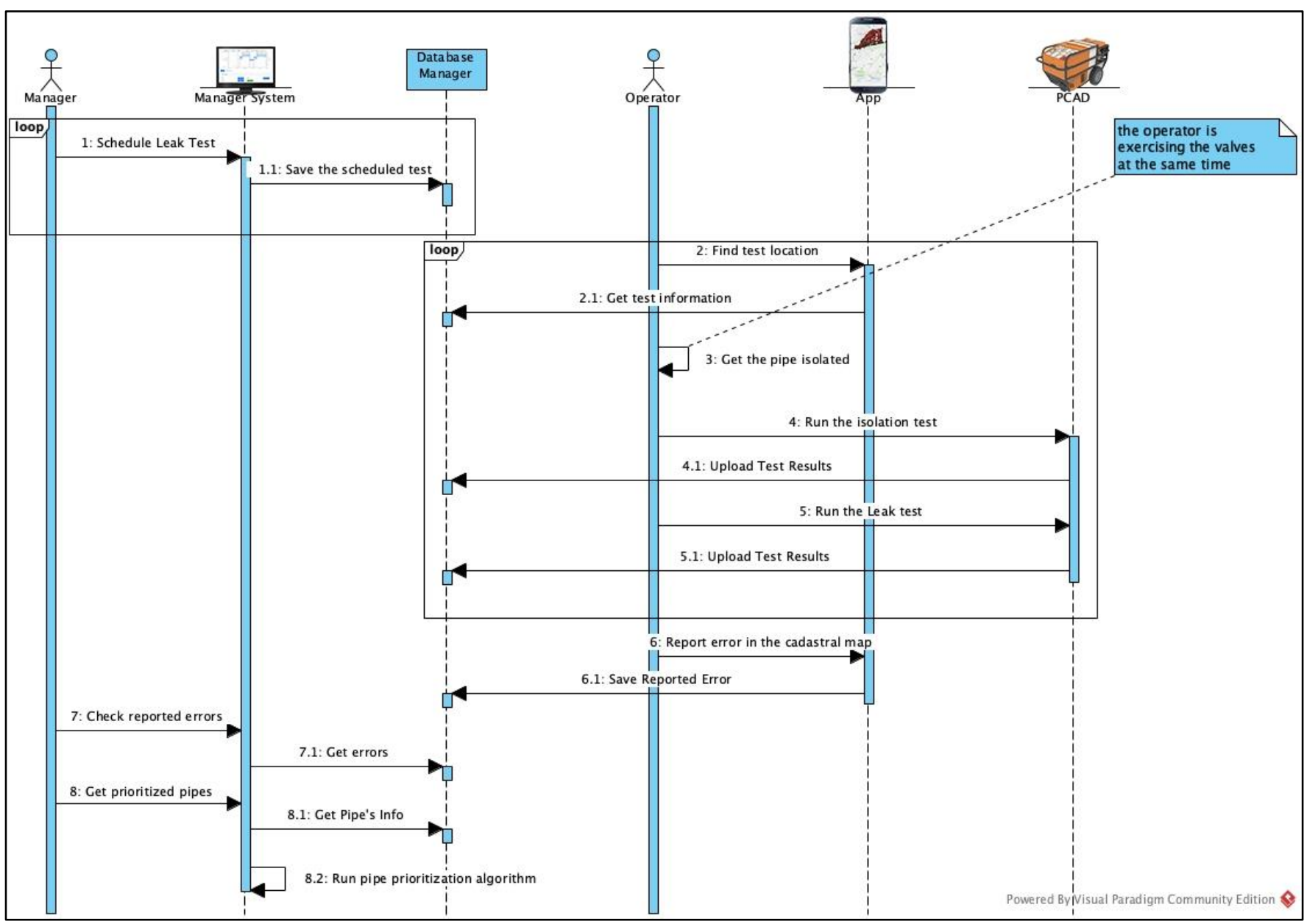

Once the isolation test is complete, the pipe leak characterisation test can start. In this test, the pump on the device is used to pressurise the pipe section. The pump starts and water is pumped from the onboard tank into the pipe. If the pipe section has one or more leaks, water will move from the tank to the pipe and out through the leaks.

By varying the speed of the pump, different flow and pressure combinations can be determined (see Figure 6). The number and values of pump's speeds (steps) are previously set through the application or the management system. And the device will hold each step until the flow and pressure stabilize or the tank runs out of water. These stable readings are used to estimate the characteristics of the pipe leaks (see Figure 7). These consist of the total initial leak area $A o$ (sum of all leak areas under zero pressure conditions) and the total head-area slope $m$ (which is linked to the dominant type of leaks in the pipe). This will allow both the size and type of leaks to be estimated.

For the dumping process it is not necessary to have the device disconnected from the water network. On this state, the device will start dumping the tank using a fix pump's speed to accelerate the process. The process will continue until the tank is empty.

Once all the necessary tests are done in that section, the PCAD can be disconnected and the user connections restored. The collected data can be used to determine the condition of the section's pipes, junctions and valves. And as part of each test, the routine operations of valve exercising and pipe flushing will have been performed on the assessed pipe section.

After one or more tests have been done, the administration system will be used to integrate and analyse the tests data. The resultant sizes and types of leaks (along with other optional criteria selected by the manager such as age, material and/or average system pressure, etc) are then used by the performance-based prioritisation algorithm. The results can be used as the base of the network's asset repair/replacement programme. 
Figure 6. Results of a leak test from a pipe in one of Cape town's DMA viewed from the administration system.

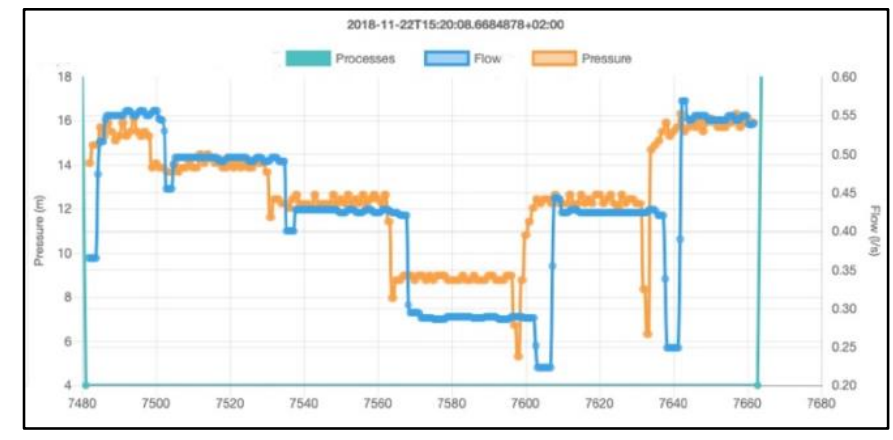

Additionally, the correlation module can be used to identify and manage the network's different trends and phenomena. As an example, a graphic presentation of the correlation between the location, material and repair priority can throw a light on the way various kinds of soil and surroundings affect different types of materials. This same concept can be used between several groups of variables, helping the network's managers make better decisions and optimize their future designs and maintenance strategies. Moreover, since the managers will have each leak's sensitivity to pressure (m), others standard operational procedures as pressure management can be optimized as well.

Finally, in the case of the condition assessment exercise being repeated on a regular time basis, the administration system's asset deterioration monitoring function can be used to evaluate the change of the assets' failure risk over time. This function also allows the user to analyse the leaks' growth trends by correlating their change in size (and/or sensitivity to pressure) with other variables like the type of crack or the pipe's material. These correlations along with the feedback given from the repair works will provide an insight into the leaks' development. Which will automatically improve the accuracy of the PCAS's deterioration model, and with it enhance the capability of its prioritization algorithm to determine the best time to repair, refurbish or replace a pipe section.
Figure 7. Leakage parameters ( $A o, C, m, N 1)$, Flow vs pressure graph and leakage's Area vs pressure graph for the stable readings of Figure 6. Displayed on the administration system.

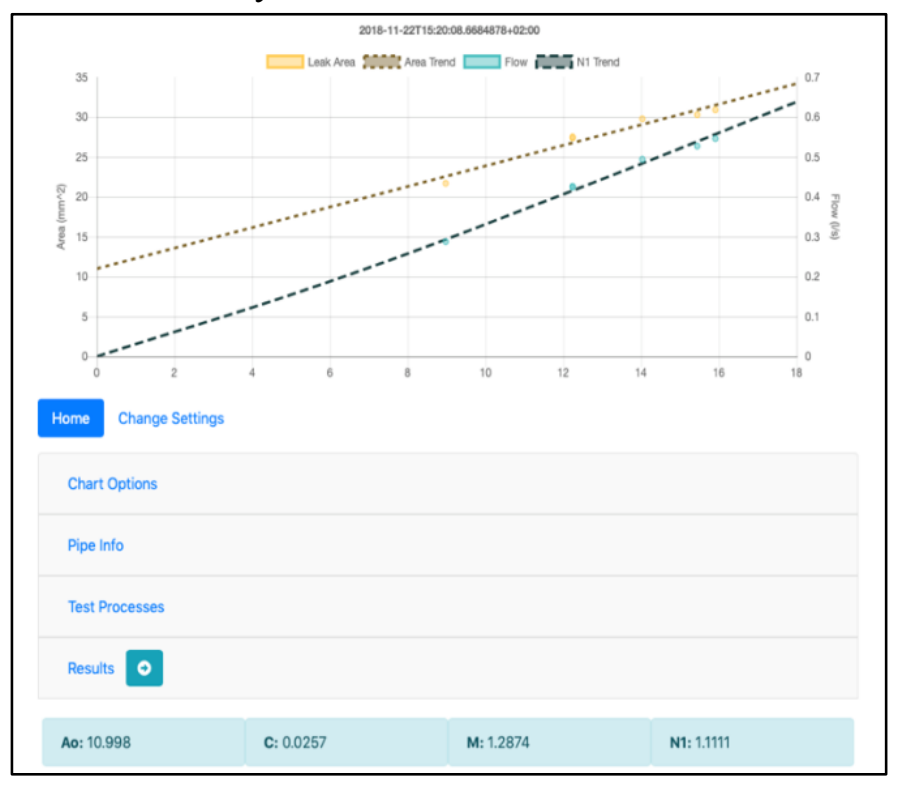

\section{Conclusion}

An integrated pipe condition assessment system was designed and tested to be used by the water utilities as part of their asset management strategies. The system is composed by one or more pipe condition assessment devices, a mobile app and an administration system.

The assessment devices and the mobile app are designed to be used by maintenance operators, while the administration system is cloud-based and meant to be used by managers and experts remotely. The system main functions include: single leak detection and characterisation, valve breach and illegal users detection, performance-based design of repair or replacement programmes, data analyses and correlation, pipe break predictor and asset deterioration monitoring.

The PCADs assess the condition of the pipes and valves through simple pressure tests detecting any size of leak, unlike most available assessment technologies. In addition, the PCADs returns the leak's initial area and its head-area slope. This unique characterisation of the leaks can also be translated into a model for the associated water losses.

The PCAS has the potential to optimize the schedule, operation and feedback of the maintenance and asset assess strategies of the water utilities. As well as it works as a leak localisation and monitoring tool. The data recollected by the conducted assessment tests can be integrated with any other related data, which correlations and analysis can have numerous benefits. 


\section{References}

ASCE (American Society of Civil Engineers) (1897) Transactions of the American Society of Civil Engineers, Vol 36. New York.

Cassa AM et al. (2010). A numerical investigation into the effect of pressure on holes and cracks in water supply pipes. Urban Water Journal, 7(2), 109-120. https://doi.org/10.1080/15730620903447613

Cassa AM and van Zyl JE (2011). Predicting the head-area slopes and leakage exponents of cracks in pipes. Proc., CCWI 2011: Computing and Control for the Water Industry: Urban Water Management - Challenges and Opportunities, Univ. of Exeter, Exeter, U.K.

Cassa AM and van Zyl JE (2013). Predicting the head-leakage slope of cracks in pipes subject to elastic deformations. Journal of Water Supply: Research and Technology - AQUA, 62(4), 214-223. https://doi.org/10.2166/aqua.2013.094

Ferrante $\mathrm{M}$ et al. (2011). Experimental Evidence of Hysteresis in the Head-Discharge Relationship for a Leak in a Polyethylene Pipe. Journal of Hydraulic Engineering, 137(7), 775-780. 7900.0000360

Fox S et al. (2017). Experimental Study Exploring the Interaction of Structural and Leakage Dynamics. Journal of Hydraulic Engineering, 143(2), 1-12. https://doi.org/10.1061/(ASCE)HY.1943-7900.0001237.

Gebhardt D (1975). The effects of pressure on domestic water suppy including observations on the effect of limited gardenwatering restriction during a period of high demand. Water $S A$, 1 April, pp. 3-8.

Greyvenstein B and Van Zyl, JE (2007). An experimental investigation into the pressure - Leakage relationship of some failed water pipes. Journal of Water Supply: Research and Technology - AQUA, 56(2), 117-124. https://doi.org/10.2166/aqua.2007.065

Jafar R et al. (2010). Application of Artificial Neural Networks (ANN) to model the failure of urban water mains. Mathematical and Computer Modelling, 51(9-10), 11701180. https://doi.org/10.1016/j.mcm.2009.12.033

Kimutai E et al. (2015). Comparison of Statistical Models for Predicting Pipe Failures: Illustrative Example with the City of Calgary Water Main Failure. Journal of Pipeline Systems Engineering and Practice, 6(4), 04015005. https://doi.org/10.1061/(ASCE)PS.1949-1204.0000196

Kleiner Y and Rajani B (2001). Comprehensive review of structural deterioration of water mains: Statistical models. Urban Water, 3(3), 131-150. https://doi.org/10.1016/S14620758(01)00033-4

Lambert A (2000) What do we know about pressure: leakage relationships in distribution systems? IWA Conference Proceedings on System Approach to Leakage Control and Water Distribution Systems Management, Brno. ISBN 807204-197-5.

Ledochowski W (1956). An analytic method of locating leaks in pressure pipe-lines. J. South Aft. Inst. Civil Eng., 6(12), 341344.
May J (1994). Pressure dependent leakage. World Water Environ. Eng., 10.

Puust R et al. (2010). A review of methods for leakage management in pipe networks. Urban Water Journal, 7(1), 25-45. https://doi.org/10.1080/15730621003610878.

Rajani B and Kleiner Y (2001). Comprehensive review of structural deterioration of water mains: physically based models. Urban Water, 3(3), 151-164. https://doi.org/10.1016/s1462-0758(01)00032-2

Romano M et al. (2010). Real-Time Leak Detection in Water Distribution Systems. Water Distribution Systems Analysis 2010, 1074-1082. https://doi.org/10.1061/41203(425)97

Sanz G et al. (2016). Leak Detection and Localization through Demand Components Calibration. Journal of Water Resources Planning and Management, 142(2), 04015057. https://doi.org/10.1061/(ASCE)WR.1943-5452.0000592

Schwaller J et al. (2015). Characterising the pressure-leakage response of pipe networks using the FAVAD equation. Water Science and Technology: Water Supply, 15(6), 1373-1382. https://doi.org/10.2166/ws.2015.101

Schwaller J and van Zyl JE (2015). Modeling the PressureLeakage Response of Water Distribution Systems Based on Individual Leak Behavior. Journal of Hydraulic Engineering, 141(5), 04014089. https://doi.org/10.1061/(ASCE)HY.19437900.0000984

Ssozi EN et al. (2016). Numerical Investigation of the Influence of Viscoelastic Deformation on the PressureLeakage Behavior of Plastic Pipes. Journal of Hydraulic Engineering, 142(3), https://doi.org/10.1061/(ASCE)HY.1943-7900.0001095

van Zyl JE and Cassa AM (2014). Modeling Elastically Deforming Leaks in Water Distribution Pipes. Journal of Hydraulic Engineering, 140(2), 182-189. https://doi.org/10.1061/(ASCE)HY.1943-7900.0000813

van Zyl JE and Clayton CRI (2007). The effect of pressure on leakage in water distribution systems. Proceedings of the Institution of Civil Engineers - Water Management, 160(2), 109-114. https://doi.org/10.1680/wama.2007.160.2.109

van Zyl JE and Malde R (2017). Evaluating the pressureleakage behaviour of leaks in water pipes. Journal of Water Supply: Research and Technology - AQUA, 66(5), 287-299.

van Zyl JE et al. (2017). Realistic Modeling of Leakage and Intrusion Flows through Leak Openings in Pipes. Journal of Hydraulic Engineering-ASCE, 143(9), 3-9. https://doi.org/10.1061/(ASCE)HY.1943-7900.0001346.

Walski T and Weir MH (2006). Modeling leakage reduction. Journal (American Water Works Association), 98(4), 147155.

Ward B et al. (2017). Deterioration modelling of smalldiameter water pipes under limited data availability. Urban Water Journal, 14(7), 743-749.

Zeng W et al. (2018). Condition Assessment of Water Pipelines Using a Modified Layer-Peeling Method. Journal of Hydraulic Engineering, 144(12), 04018076. https://doi.org/10.1061/(ASCE)HY.1943-7900.0001547 